\title{
A DEEP INSIGHT ON DIABETIC NEUROPATHY: THE SILENT COMPLICATION OF DIABETES, WITH INPUTS ON ITS CAUSES, DIAGNOSIS, PATHWAYS, AND TREATMENTS
}

\author{
NIKITA SARASWAT ${ }^{1 *}$, PHOOL CHANDRA ${ }^{2}$, NEETU SACHAN $^{2}$ \\ ${ }^{1}$ Department Pharmacy, Pranveer Singh Institute of Technology, Kanpur, Uttar Pradesh, India. ${ }^{2}$ Department of Pharmacy, School of \\ Pharmaceutical Sciences, IFTM University, Moradabad, Uttar Pradesh, India. Email: nikita.saraswat07@gmail.com
}

Received: 13 July 2018, Revised and Accepted: 03 August 2018

\begin{abstract}
Objective: The incidence of diabetic neuropathy (DNP) is a prominent complication for people suffering from diabetes. DNP is a common complication in patients suffering from diabetes, and it is affecting approximately more than $50 \%$ of the population where the nerves are affected by high glucose levels.

The aim of the review paper is to inspect the complications, causes, diagnosis, pathogenesis, treatments, pathways, and management of DNP as all these factors play important role in the management of DNP. This paper also aims to identify the potential cures and the side effects if any associated with the commonly used treatments in conditions of DNP.
\end{abstract}

Methods: The data collected for reviewing was by studying the published researchers from PubMed, Web of Science, Medline, Science Direct, Excerpta Medica Database, Cochrane, Elton B. Stephens Company (EBSCO), and Google open access publications from the year $1995-2017$.

Results: We have concluded on an interpretation that the drugs for treating DNP are managing the pain and controlling glucose levels but are reportedly causing major side effects. Hence, attention must be given to the potential risk factors for neuropathy and development of formulations with minimal side effects and a potential cure. We have focused on the recent researches, emerging problems, and techniques for identifying the patients suffering from DNP.

Conclusion: The incidence of DNP is a prominent complication for people suffering from diabetes. Although the treatment available currently focusses on the pain management in DNP, attention must be given to the potential risk factors for neuropathy and development of formulations with minimal side effects and a potential cure.

Keywords: Diabetic neuropathy, Diabetes mellitus, Distal symmetric polyneuropathy, Chronic complications, Antidepressant, Ethnomedicine, Pathways of diabetic neuropathy.

(C) 2018 The Authors. Published by Innovare Academic Sciences Pvt Ltd. This is an open access article under the CC BY license (http://creativecommons. org/licenses/by/4. 0/) DOI: http://dx.doi.org/10.22159/ajpcr.2018.v11i12.28447

\section{INTRODUCTION}

Diabetes mellitus (DM)

Diabetes is a common disease associated with neurological complications which are a pressing problem for the patient throughout the world [1]. A study revealed that at least half of the people who have Type 1 diabetes develop some form of neuropathy in their lifespan [2]. This is the most common complication of DM, wherein type 1 diabetes the distal polyneuropathy is symptomatic even after many years of diagnosis, while the Type 2 patients may be suffering from neuropathy at the time of diagnosis [3].

DM is a disorder, in which the elevated blood glucose levels are exhibited due to absence (partial or total) of insulin levels in the body. It is a huge problem among people aged 45-64 years, and people are more likely to suffer from complications of diabetes such as diabetic retinopathy, diabetic neuropathy (DNP), thirst, itchy skin, delay in wound healing, and multiple other clinical complications $[3,4]$. DM is a prolonged disease which has been prevalent, and it is increasing all around the world. The pattern is predicted to double in the coming years as the countries are heading to have more aged people than now.

The major problem faced in case of diabetes is that the people who are suffering from it are still unknown about the disease. DM is common in people who have physical inactivity, obesity, and weight issues [5].

According to the World Health Organization, the world has a total population of about 350 million diabetics which is supposed to increase by $50 \%$ until the year 2030 . It has also been proposed that diabetes would be one of the $7^{\text {th }}$ leading causes of death among the people [6].

This review will give an insight into the complications of diabetes which is DNP. The novelty of the paper is to showcase the types, symptoms, mechanisms, available treatment, and side effects of treatment for DNP.

\section{Types of DM}

Based on the classification, there are three types of DM commonly two types of diabetes are known to people who are type $1 \mathrm{DM}$ and type $2 \mathrm{DM}$. The third uncommon one is gestational diabetes [7]. In all the categories, hyperglycemia is a common characteristic. The type 1 diabetes is a result of the partial or total lack of insulin production. The type 2 diabetes is a consequence of insulin resistance, impaired insulin secretions, and heightened glucose production in various cases [8].

The third type which isgestational diabetes is common in pregnant women who have a change of developing diabetes during their pregnancies. Although the situation goes back to normal after the pregnancy is over, the chances of them developing diabetes later in life are more likely than the rest. Approximately $4 \%$ of pregnant women in the United States tend to acquire gestational diabetes [8]. A research study conducted in India by Zagar et al. stated that approximately $3.8 \%$ gestational DM is dominant and with the increased age of patient the chances of diabetes are substantial [9]. As per the National Health and Medical Research Council (2005) guidelines, for the management of Type 2 DM, the glucose levels for non-diabetics and diabetics are as mentioned in Table $1[9,10]$. 
Complications of diabetes

Depending on the severity of the disease, diabetes can be classified as following types:

- Acute complications (or diabetic emergencies)

The acute complications of diabetes are diabetic ketoacidosis and hypoglycemia

- Chronic complications

The problems arising in chronic diabetes are classified as either

a. Microvascular complications or

b. Macrovascular complications.

The problems associated with microvascular complications are diabetic retinopathy [11-13]. Diabetic nephropathy and diabetic skin problems (the "diabetic foot") are also among the major microvascular complications of diabetes. Whereas the macrovascular complications can cause problems such as arteriosclerosis, peripheral vascular disease/coronary heart disease, hypertension, myocardial infarction, and cerebrovascular disease $[14,15]$

\section{DNP}

DNP is a disease or a clinical condition where the peripheral nerves are damaged as a result of DM. This causes a major effect on the autonomic as well as the somatic nervous system [16]. It has been reported that diabetic peripheral neuropathy is very painful and this condition can only be relieved by medication. The various classifications of diabetic neuropathies are mentioned in Table 2 [17].

Nearly $8 \%$ of the newly diagnosed patients have found to shown diabetic neuropathic conditions, whereas $50 \%$ patients with long-standing disease showed the symptoms of DNP $[18,19]$. It has been observed and reported that the DNP is more severe and painful at night $[20,21]$.

Table 1: Blood glucose levels [9 and10]

\begin{tabular}{|c|c|c|}
\hline Types & $\begin{array}{l}\text { Pre-prandial } \\
\text { (m mol/l) }\end{array}$ & $\begin{array}{l}\text { Post-prandial } \\
(\mathrm{m} \mathrm{mol} / \mathrm{l})\end{array}$ \\
\hline \multicolumn{3}{|l|}{ For non-diabetics } \\
\hline Diabetes implausible & Below 5.5 & Below 5.5 \\
\hline $\begin{array}{l}\text { Diabetes ambiguous } \\
\text { (must be rechecked by } \\
\text { a medical practitioner) }\end{array}$ & $5.5-6.9$ & $5.5-11$ \\
\hline Diabetes possible & 7 or above & 11.1 or above \\
\hline \multicolumn{3}{|l|}{ Diabetics } \\
\hline Low ("hypoglycemia”) & Below 4 & Below 4 \\
\hline Normal & $4-6$ & $4-7.7$ \\
\hline Moderate & $6.1-6.9$ & $7.8-10.9$ \\
\hline High ("hyperglycemia") & Above 7 & Above 11 \\
\hline
\end{tabular}

Table 2: Classification of diabetic neuropathies-based on location of affected area $[23,24]$

\footnotetext{
Symmetric

Diabetic polyneuropathy

Autonomic neuropathy

Insulin neuritis

Polyneuropathy post-ketoacidosis

Polyneuropathy along with glucose impairment

Diabetic cachexia

Demyelinating polyneuropathy with DM

Asymmetric

Mononeuropathy

Radicucloneuropathy (cervical, thoracic, and lumbosacral)

Ulnar neuropathy (elbow)

Cranial neuropathy

Median neuropathy (wrist)

Peroneal neuropathy (fibular head)
}

Our review paper focuses on the collection of authentic information about DNP, the plants extract which are potential cures for the DNP are being used traditionally by people under ayurveda for the treatment of diabetes which have proved to be very useful till date therefore more research is required in the development of an ayurvedic preparation from herbal extracts as a standard treatment for curing diabetes and diabetic neuropathy.

Underneath we have discussed the synthetically prepared medical formulations and different classifications of drugs being used currently in the treatment of Diabetic Neuropathy and most importantly in controlling the inflammation and pain. As a painful neuropathy condition is a common and discomforting problem with prolonged DM. Therefore, commonly used tricyclic antidepressant drugs and other analgesics have been used to get relief from the painful neuropathic pain in some patients, but there is no agent who is completely giving relief from the pain, and high doses of the medications are reportedly causing adverse reactions [15]. The complications of diabetes cause diabetic neuropathies, whereas the neuropathic condition can arise by multiple factors shown in Fig. 1.

\section{Diabetic symmetric distal polyneuropathy (DSDP)}

The DSDP associated with autonomic neuropathy is a commonly observed DNP where the distal distribution of sensory and motor symptoms and signs along the length. The autonomic association with DSDP is a crucial part of the clinical complexes thus both of them are noted and considered together [22].

\section{Search engine}

A thorough review of published articles on PubMed, Web of Science, Medline, Science Direct, Excerpta Medica Database (EMBASE), Cochrane, EBSCO, and Google open access by searching keywords such as "DNP, DM, Medications for DNP" was performed. In addition, articles were also obtained from online sites, newspapers, peer review, magazines, and Google Scholar. The review contained information from published sources on diabetes, DNP, and its treatment.

\section{Data abstraction and analysis}

We have attempted to review the published researches on DNP, its pathways, treatment, and the side effects observed. This paper also focuses on the research conducted from 1995 to 2017 on patients suffering from DNP. The medications given as a treatment for treating DNP has shown side effects.

\section{Causes}

Major causes of neuropathy

DNP is a nervous disorder which is majorly seen in people suffering from diabetes. Whereas, when we categorize them, there are different types and causes of DNP. Numerous researches these days are directed to study the nerve damage caused by continuous high levels of glucose in blood in case of a diabetic patient.

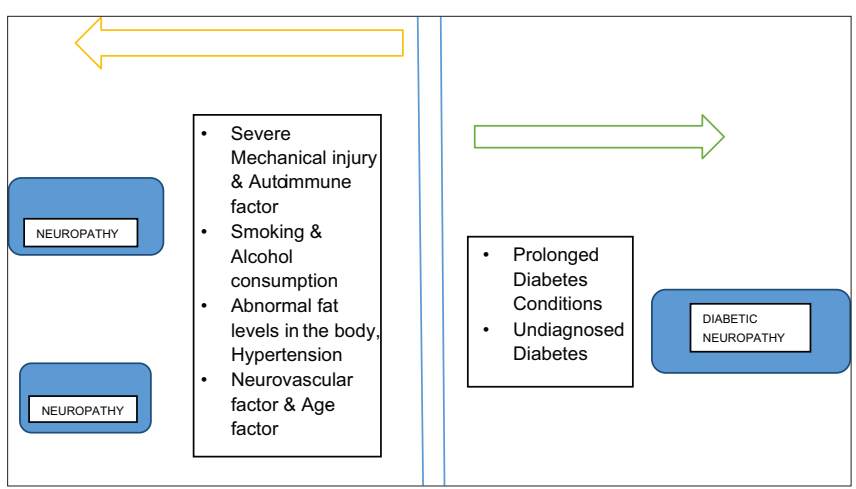

Fig. 1: Probable causes of different types of neuropathy 
Table 3: Factors contributing for development of neuropathy $[26,27]$

\begin{tabular}{l}
\hline Heavy alcohol intake \\
Smoking \\
Suffering from diabetes for long time \\
Hypertension \\
Age factors \\
HLA DR3/4 phenotype \\
Prolonged dyslipidemia \\
Long height
\end{tabular}

Multiple factors or combination of factors altogether can also cause nerve damage which is as follows and illustrated by Table 3 and Fig. 1:

- Abnormal fat levels in the body, prolonged duration of diabetes, and metabolic factors with potentially low levels of insulin

- A severe mechanical injury to nerves as in case of carpal tunnel syndrome

- Certain autoimmune factors or disorders which cause nerve inflammation

- Possible inherited traits which are responsible for increasing the susceptibility to nerve diseases

- Multiple neurovascular factors which result in leading damage to the blood vessels which are responsible for carrying oxygen and nutrients to nerves.

- Habits and lifestyle factors such as smoking, alcohol consumption, and drug abuse are also responsible for nerve damage in prolonged duration $[25,26]$

\section{Diagnosis}

The medical practitioners and diabetologists must refer the patients suffering from neuropathies to more specialized testing by neurologists and accessing of complex and detailed parameters to know the extent of damage, possible zones affected, prior detection of neuropathies, and sensitive/prone areas of damage during chronic diabetes condition. A lot of different scoring systems and inflammatory parameters are monitored for generating a detailed result of neuropathies. An amalgamation of typical symptoms of neuropathy with sensory loss and lack of reflexes is a direct indication of DNP. The condition of DNP has to be checked and carefully examined annually or biannually for better analysis.

A patient or anyone suspected of diabetes has to get screened for DNP by observing methods such as pinprick test, temperature test, perception of vibration test using tuning fork (128Hz tuning fork), checking ankle reflexes, and examining the distal hallux sensitivity using $10 \mathrm{~g}$ monofilament pressure sensation [28]

Usually, multiple tests are performed which makes the testing $87 \%$ sensitive in the detection of DNP. A loss of sensation, perception, and reduced vibration is observed by the diagnosis test performed using a $10 \mathrm{~g}$ monofilament which predicts foot ulcers therefore it is very popularly being used in the diagnosis of Diabetic Neuropathy (DNP). The damage to the nerves and the extent of damage is easily identified by using monofilaments and studies have also shown that clinical tests performed are a good diagnosis of prospected risk for foot ulcers [29].

Therefore, the feet must also be examined and inspected for any deformities, ulcers, calluses.

\section{Physiological examination of DNP}

The duration and degree of hyperglycemia is a cause for the severity, frequency, and progression of neuropathy. Multiple types of research such as diabetes control and complication trials have stated that the incidences of neuropathy have improved and stabilized by controlled glucose levels [30].

The staging of clinical neurological scales can be used for assessing the severity of DNP as mentioned in Table 4 [31].
Table 4: Different staging's of neuropathy [31]

\begin{tabular}{ll}
\hline Staging & Signs \\
\hline NO & No sign of neuropathy \\
N1a & Signs reported but no symptoms of neuropathy \\
N2a & Symptomatic but mild diabetic polyneuropathy observed \\
N2b & Severe symptomatic diabetic polyneuropathy \\
& reported (as in N2a but patient unable to heel walk) \\
N3 & Disabling diabetic polyneuropathy \\
\hline
\end{tabular}

\section{Other investigating methods for DNP}

Imaging is an advantageous tool for the diagnosis and management of DNP. Therefore, in clinical setups, the magnetic resonance imaging performed for the cervical, thoracic, or lumbar regions could be a great help in identifying the symptoms of DNP.

\section{Quantitative sensory testing}

It is a test performed to interpret the ability of a person to detect sensory stimuli. Such sensory tests are used to identify the zones where the sensory losses have occurred majorly. These tests will work the best when there is complete cooperation, concentration, and comprehension of the patient during testing.

\section{Semmes-Weinstein monofilaments}

In this test a set of nylon filaments are called the monofilaments is used which clips at a preset force on application to the testing site of numbness or nerve damage or the site to be tested for DN (Diabetic Neuropathy). These filaments give pretty accurate results and are being widely used in clinical practice for identification of diabetic patients who are at higher risks of DNP and neuropathic foot ulcerations. The prediction of neuropathic ulceration can be showcased if the subject is unable to perceive a $10 \mathrm{~g}$ monofilament.

\section{Vibrations and perceptions}

Vibration perception thresholds (VPTs) are assessed by several devices for testing a myelinated fiber function. The VPT increases with the age of individuals and they are higher in the lower extremity areas. They are used to estimate the risks of ulcerations and neuropathies. An abnormal reading of $25 \mathrm{~V}$ is linked to high risks.

\section{Computer-assisted sensory examination}

Using a computerized device for observing and analyzing the zones of touch, pressure, vibration, temperature changes thresholds is a state of art technique used in clinical trials for identifying neuropathic zones (the zones which are highly affected by prolonged diabetes and have now caused nerve damage, loss of sensation in limbs, tingling feeling etc.). This has been used successfully in many therapeutic interventions [18].

\section{Autonomic functionality testing}

The autonomic dysfunction of the cardiovascular region can be assessed by using Ewing and Clarke's battery for five tests which are as follows:

- An average of inspiratory and expiratory heart rate difference with deep breaths

- $\quad$ The 30:50 ratios

- The Valsalva ratio

- The diastolic blood pressure response to the isometric exercises

- The fall in systolic blood pressure to standing [32].

\section{Mechanisms}

\section{Pathological mechanism}

The radical increase in diabetic patients creates a major problem in the care of neuropathy. Therefore, the need to explore the pathogenesis to develop effective treatment was required.

Recent clinical research and studies have shown the characteristics of the pathophysiology of DNP. The pathology was found to be a progressive nerve fiber loss which gave rise to clinical symptoms 
such as paresthesia, pain, and loss of sensation. The loss of nerve fiber takes the form of a distal gradient. Other symptoms like endoneurial microangiopathic changes are an important feature of peripheral nerve pathology, and this creates a negative impact on the nerve fiber density.

People experiencing impaired glucose tolerance levels are also identified with vascular changes, loss of distal nerve fiber, and pave the way the for loss of nerve fibers in the nerve stem of lower limbs: $[33,34]$.

The major multiple pathogenic mechanisms which are the underlying causes of nerve damage and nerve fiber losses are polyol pathway, reactive oxygen species (ROS), glycation, and altered protein kinase $\mathrm{C}$ (PKC) activity [33].

The development of DNP pivots around many factors and processes such as hyperglomerular filtration, inflammation channels, metabolic pathways, and oxidative stress conditions [34]. When the diabetic condition persists then the arterioles are dilated, the blood flow and glomeruli are increased and an elevation in intraglomerular pressure is noted.

These changes in the physiology induce inflammation as well as oxidative stress in the glomeruli, therefore, leading to excessive production of extracellular matrix which leads to the gradual development of glomerulosclerosis. There is no specific therapy designed to cure DN. Therefore, managing hyperglycemia, dyslipidemia, and hypertension is the ultimate cure for treating it to date.

\section{DNP: Pathways associated}

Over the last 30 years, the research in the field of DNP has been concentrated on these pathways involved in the development of DNP. The main components included in the study are the redox and metabolic state of dorsal root ganglions and Schwann cells. A lot of work has been focused on the interpretation of polyol pathways, hexosamine pathways, and pathways of isoforms of PKC, accumulation of (advanced glycation end products [AGEs]) in the DNP exhibiting nerve as well as the excess glucose and fatty acid reflux.

\section{Polyol pathway}

The excess amount of glucose is eventually converted by aldose reductase into sorbitol which develops an osmotic imbalance in the cell. This leads to osmotic stress and efflux of myoinositol and taurine. Therefore, myoinositol which is an integral part of sodium/potassium ATPase harms the normal physiology of the nerve cell.

Another improper activity is occurring along with the prior abnormality which the aldose reductase activity was impending a decrease in cellular stores of nicotinamide adenine dinucleotide phosphate which is required for generation of NO and regeneration of glutathione (an essential antioxidant).

The pathway leads to the formation of ROS which altogether disturbs the physiology of cell causing cellular dysfunction and ROS-mediated cell injury. The hypothesis is called "metabolic reflux hypothesis." [35]

A set of preclinical studies performed on streptozotocin (STZ) rat models of T1D highlighted the activation of the polyol pathway and outlined the impaired peripheral nervous system (PNS) structures and functions [36].

\section{Hexosamine and PKC pathways}

An increased pace of glycolysis due to increased glucose also increases the metabolic disrupting pathways which are altogether speeding the neuronal injury.

Fructose-6-phosphate, the glycolysis intermediate enters the hexosamine pathway and has to undergo a chain of reaction leading to the formation of uridine 5-diphosphate-N-acetylglucosamine (GlcNac). GlcNac is a sugar moiety which has the capacity to bind serine/threonine residues on SP-1, promoting lipid dyshomeostasis, inflammation, and injury of complication-prone tissues basically including the peripheral nerves [37].

\section{End products of advanced glycation}

In case of Maillard reaction, the amino acids react with glucose on protein molecules leading to the formation of Amadori products. They in a long time produce irreversible glycation products like AGEs.

The crosslink formed between AGEs and essential proteins creating cellular damage and altered functioning. Secondarily, AGE shows binding with receptor of AGE (RAGE) and potentiates downstream signaling cascade which is mediated by activation of nuclear factor NF$\mathrm{kB}$, this is poisonous.

A huge loss of neurotrophic support, vasoconstriction, and inflammation are recorded in case of a rodent PNS after AGE activated its receptor RAGE [38]. Accumulation of AGE has been reported in patients suffering from DNP as well as T2D [39].

\section{DNP - treatment}

\section{Antidepressants}

Tri cyclic antidepressants (TCA's)

The TCA's - amitriptyline, nortriptyline, and imipramine function by inhibiting reuptake of norepinephrine and serotonin. NICE guidelines have recommended the use of amitriptyline as the first-line drug in treating the DNP. Nortriptyline/amitriptyline must be given at low doses like, e.g., $10 \mathrm{mg}$ at night to an increased dose of $150 \mathrm{mg}$ on week 21 .

A lot of cholinergic side effects have been reported and patient is opting for TCA drug withdrawal. Multiple side effects such as dry mouth, blurred vision, sedation arrhythmias, urinary retention, orthostatic hypotension, and weight gain. Comparatively, nortriptyline is better tolerated due to lesser anticholinergic side effects. There are some contraindications of using TCAs: Patients of myocardial infarction, cardiac conduction defects, prostatic hypertrophy, and closed-angle glaucoma must refrain from using TCAs [40-45].

\section{Serotonin-norepinephrine reuptake inhibitors}

According to the NICE guidelines, the first-line drug for the treatment of painful DNP is duloxetine. This drug has a balanced action on both norepinephrine and serotonin reuptake at the presynaptic junction. The drug has equal antidepressant and analgesic properties. The initial doses are given as low as 30-60 mg and increased to $120 \mathrm{mg}$ on the basis of side effects and tolerance [46-50].

It is always recommended to keep low initial doses in starting of treatment followed by a gradual increase in the dose concentration. The commonly reported side effects are sweating, dry mouth, nausea, somnolence, and sometimes hepatitis. Patients consuming them have reported a loss of appetite. The drug is contraindicated in patients suffering from glaucoma, liver failure, and renal failure. Hypertensive patients must be cautious in using this medication as it has shown an increase in blood pressure levels.

\section{Anticonvulsants}

Gabapentin and pregabalin are very commonly used anticonvulsants in the treatment of neuropathic pain. They work by binding the a- $2 \mathrm{~d}$ subunits of the calcium channel and thus reduce the influx of calcium. This leads to a decrease in the release of calcium-regulated excitatory neurotransmitters like glutamate. Initially, the dose of glutamate is $300 \mathrm{mg}$ which can be increased up to $1800-3600 \mathrm{mg}$ after a few weeks.

Pregabalin is a second-line drug for treatment and the side effects of both the drugs are drowsiness, dry mouth, weight gain, diarrhea, and edema [51-53].

\section{Opioids}

Opioids have shown moderate effectiveness in the treatment of painful DNP. Oxycodone and tramadol are commonly used in the treatment after 
other drugs have failed to show any effectiveness or have shown adverse reactions after prolonged used. Tramadol is a weak inhibitor of serotonin and norepinephrine reuptake and acts as a centrally acting opioid agonist. A recommended dose of $50 \mathrm{mg}$ in starting dose to $400 \mathrm{mg}$ dose after few weeks is advised during the treatment. The common side effects of the drug are vomiting, dry mouth, nausea, and constipation [54].

\section{Topical treatments}

As capsaicin binds with transient receptor potential vanilloid 1 receptors which are present on the surface of nociceptive nerve fibers, therefore, applying capsaicin-containing topical agents have proved to be helpful in treating neuropathic pain.

The patients applying cream themselves must use gloves while applying the cream and avoid contact with mucous and eyes. The benefit and role of $8 \%$ capsaicin are currently under review in the treatment of painful DNP [55]

Many patches, creams, and ointments have been used for treatment but a comparative and combinational study concluded that gabapentin, pregabalin, and duloxetine were equally effective [56]

The drug amitriptyline has proved out to be equally effective as pregabalin, but with more side effects in comparison to the latter. A combination drug of gabapentin and nortriptyline was proved to be better analgesic than a single drug therapy as observed in a crossover trial [57].

We have collected information from published researches and databases such as EMBASE, EMB reviews, Medline, and Cochrane central register of controlled trials for studying the effective treatment of DNP by the systematic review process. A lot of double-blind, randomized trials were conducted and drugs such as non-steroidal anti-inflammatory drugs, opioid drugs, ion channel blockers, antidepressants, and anticonvulsants were used in treating patients. Table 5 states the research's conducted by scientists for treatment for DNP and results were collected and evaluated.

The treatment measures for management of the risk factors for diabetes are sufficient to prevent any progression of the disease and stabilize it, therefore, preventing it from getting worsened.

Anticonvulsant [58-61] trails reported side effects such as dizziness, liver derangement, and somnolence. The antidepressant $[61,62]$ therapy reflected side effects such as vomiting, headache, pain, nausea and itching. No exact adverse reaction other than nausea was published for ion channel blockers, [63] whereas opioids [60,64] showed severe adverse reactions such as constipation, nausea, vomiting, somnolence, and headache.

\section{Pain management in DNP}

Experiencing the neuropathic pain is the most common feature of neuropathy. Although there are multiple medications available, still the management of the pain is crucial. As recommended by American Academy of Neurology in 2011 guidelines, pregabalin $75-150 \mathrm{mg}$ is the drug recommended for the treatment of neuropathic pain. Drugs such as sodium valproate, gabapentin, amitriptyline, and imipramine are also recommended for the management of diabetic pain $[66,67]$. Other topical agents such as transdermal lidocaine and capsaicin are also useful for the management of pain

\section{Animal models}

Animal models for research studies on diabetes and DNP

STZ model

In previously mentioned researches, a lot of drugs were tested for treating neuropathy before the tests DM, and subsequently, DNP was induced. Here are some methods for inducing diabetes and DNP.

An intraperitoneal (i.p) injection of STZ (60 mg/kg dissolved in $0.9 \%$ $\mathrm{NaCl}$ with a $\mathrm{pH}$ of 4.0 ) was given to rats for inducing DM $[68,69]$.

In this research, other seven rats were grouped as control, and therefore, they did not receive any amount of drug. Now both the groups were tested for blood glucose levels using glucose oxidase reagent strips by obtaining blood from the tail tips.

Rats with a glucose level of $\geq 250 \mathrm{mg} / \mathrm{dl}$ were included in the study which proved to be successfully induced with diabetes. These rats were then used for conducting comparative studies as well as to perform activity analysis of certain drugs which have proved to cure DNP by histologically examining the sciatic nerve or performing motor function tests successfully.

\section{Alloxan model}

Alloxan is taken by the liver after administration which acts as a protective agent against the ROS. Therefore, it is not vulnerable to damage $[70,71]$. There are different mechanisms reported for alloxan which state that it damages the beta cells of the pancreas by oxidation of the -SH groups, and especially of glucokinase [72] as well as creates a disturbance in the homeostasis of intracellular calcium ions. [73] When diabetes is induced using alloxan, then mice are administered $50-200 \mathrm{mg} / \mathrm{kg}$, whereas rats are given $40-200 \mathrm{mg} / \mathrm{kg}$ of alloxan drug using i.p or subcutaneous (s.c) injection as the route of administration.

Table 5: List of conducted trails for treating neuropathy [58-65]

\begin{tabular}{|c|c|c|c|c|c|c|c|c|}
\hline Drug Class & $\begin{array}{l}\text { Trial } \\
\text { conducted by }\end{array}$ & $\begin{array}{l}\text { Active drug } \\
\text { molecule }\end{array}$ & Dose (mg) & $\begin{array}{l}\text { Age } \\
\text { (mean) }\end{array}$ & $\begin{array}{l}\text { Treatment } \\
\text { period }\end{array}$ & Number & Design & $\begin{array}{l}\text { Follow-up } \\
\text { (efficacy of } \\
\text { treatment) }\end{array}$ \\
\hline Anticonvulsant & $\begin{array}{l}\text { Kochar } \\
2002[58]\end{array}$ & $\begin{array}{l}\text { Sodium } \\
\text { valproate }\end{array}$ & 1200 & 56 & 4 weeks & 57 & Parallel & $\begin{array}{l}\text { At completion } \\
\text { of treatment }\end{array}$ \\
\hline Anticonvulsant & $\begin{array}{l}\text { Beydoun } \\
2006 \text { [59] }\end{array}$ & Oxcarbazepine & $600 / 1200 / 1800$ & 60 & 16 weeks & 347 & Parallel & $\begin{array}{l}\text { At completion } \\
\text { of treatment }\end{array}$ \\
\hline Anticonvulsant & $\begin{array}{l}\text { Dogra } \\
2005[60]\end{array}$ & Oxcarbazepine & 1445 (mean) & 60 & 16 weeks & 146 & Parallel & $\begin{array}{l}\text { At completion } \\
\text { of treatment }\end{array}$ \\
\hline Anticonvulsant & $\begin{array}{l}\text { Eisenberg } \\
2001[61]\end{array}$ & Lamotrigine & $25-400$ & 55 & 8 weeks & 59 & Parallel & $\begin{array}{l}\text { At completion } \\
\text { of treatment }\end{array}$ \\
\hline Antidepressant & $\begin{array}{l}\text { Raskin } \\
2005 \text { [62] }\end{array}$ & Duloxetine & $60 / 120$ & 58.8 & 12 weeks & 348 & Parallel & $\begin{array}{l}\text { At completion } \\
\text { of treatment }\end{array}$ \\
\hline $\begin{array}{l}\text { Ion channel } \\
\text { blocker }\end{array}$ & $\begin{array}{l}\text { Wright } \\
1997 \text { [63] }\end{array}$ & Mexiletine & 600 & 50 & 3 weeks & 31 & Parallel & $\begin{array}{l}\text { At completion } \\
\text { of treatment }\end{array}$ \\
\hline Opioid & $\begin{array}{l}\text { Watson } \\
2003[64]\end{array}$ & $\begin{array}{l}\text { Controlled } \\
\text { release } \\
\text { oxycodone }\end{array}$ & $10-80$ & 63 & 4 weeks & 45 & $\begin{array}{l}\text { Crossover, } \\
\text { no washout }\end{array}$ & $\begin{array}{l}\text { At completion } \\
\text { of treatment }\end{array}$ \\
\hline Anti-depressant & $\begin{array}{l}\text { Goldstein } \\
2005 \text { [65] }\end{array}$ & Duloxetine & $20 / 60 / 120$ & 60 & 12 weeks & 457 & Parallel & $\begin{array}{l}\text { At completion } \\
\text { of treatment }\end{array}$ \\
\hline
\end{tabular}


These concentrations are 3 times higher than the dose given through intravenous (i.v) route [74]. To create long-term diabetes in rabbits, a dose of $100 \mathrm{mg} / \mathrm{kg}$ of alloxan was given [75].

\section{DISCUSSION}

Diabetes causes a major effect on the central nervous system such as anorexia, phobias, depression, loss of memory, and reasoning skills are also affected by this condition. Diabetes is a prevalent condition which is commonly manifested as distal symmetric polyneuropathy through many other patterns of nerve injury occurs. As of now, the most effective treatment for controlling the neuropathy are monitoring glucose controls and pain management. Controlling the glucose causes a substantial decrease in the neuropathy for type 1 diabetes though the effects are substantially less in cases of type 2 diabetes patients. Researches have quoted that using anticonvulsants and antidepressants as a therapy for treating pain during management of DNP is fruitful; however, the identification of disease-modifying therapies are essential when there is a lacuna of disease-modifying therapies for treating DN.

More studies are required to explore therapies for treating DNP and finding a suitable cure. In the recent years, diabetologists and neurologists are focusing the associated problems from diabetes majorly like DNP which is a distressing problem in people suffering from diabetes. Medications such as opioids, antidepressants, anticonvulsant, ion channel blockers have been used frequently to prevent worsening of the disease.

Many reviews have highlighted that people suffering from complications of diabetes require multiple therapies, extreme care, and considerations to maintaining good health [76]. Therefore, a herbal formulation with no side effects is required for curing diabetes-related disorders like DNP.

We have deeply reviewed many research papers some of which have recommended the incorporation of neurotrophic factors for nerve regeneration which is a good source for treating neuropathic conditions [77]. Some papers have also mentioned the use of active drug molecules, which will undergo changes or alterations in the gene expressions to repair the degenerated nerves and cure the DNP conditions [78]. A popularly acceptable choice of drug-ethnomedicine must be used for treatment of DNP with no notable side effects [79] is also urged by the patients as multiple herbal sources have proved beneficial in treatment of diabetes [80] and many lifestyle disorders in recent years.

\section{Inference}

Our interpretation of the review is that in coming years, the diabetic population will raise high as compared to the numbers in 2017. As DNP is a complication reported in patients, especially when diabetes becomes chronic. The nerve damage and pain problems are a major concern among the patients and physicians, but drugs available in the market are only preventing the progression of the disease and the ultimate cure still to be explored.

The oral hypoglycemic agents have proved effective in the treatment of Type 2 diabetes [81] therefore it can be taken into consideration that using oral formulations for treating DNP ill also prove to be effective and with least side effect.

\section{CONCLUSION AND FUTURE PROSPECTIVE}

A huge number of side effects are being reported in every trial conducted for treating DNP. Moreover, curbing the pain can solve the pain issues in neuropathic nerves momentarily, but healing the damaged nerves with a potential cure could be an agenda for new researches for treating DNP.

Therefore, developing formulations to exhibit the ultimate cure, relief with not much reported adverse reactions is the need currently as well as for further benefits. Our future research must be focused on ethnomedicine as a potential cure for DNP with reportedly lesser adverse reactions. A complete cure to the problem is yet to be discovered, although researches are being conducted using natural sources and their herbal extracts which might help in reviving the damaged nerves and resolving the core cause, thus treating DNP.

\section{AUTHORS CONTRIBUTION}

All authors have contributed equally and immensely in writing this paper. Nikita Saraswat the first author has deeply reviewed and written the paper with regular contributions from Dr. Phool Chandra and Dr. Neetu Sachan. Dr. Phool Chandra suggested the title for review, material for literature review which broadened the scope of the article. Dr. Neetu Sachan has contributed largely in writing the review paper with her valuable suggestions, insights, and guidance. She has helped in the preparation of the paper in the appropriate format and in the right direction.

\section{CONFLICT OF INTEREST STATEMENT}

There is no conflict of interest in this review paper.

\section{REFERENCES}

1. Feldman L, Nave KA, Jensen TS, Bennett DL. New horizons in diabetic neuropathy: Mechanisms, bioenergetics and pain. Neuron 2017;93:1296-313

2. International Diabetes Federation. Diabetes Atlas. $6^{\text {th }}$ ed. 2014. Available from: http://www.diabetesatlas.org. [Last cited on 2017 Nov 12

3. Maji D, Maji T. Neuropathy is the commonest long term complication of Type 2 diabetic individuals at diagnosis. Diabet Metab 2003;2003:2373.

4. American Diabetes Association. Diagnosis and classification of diabetes mellitus. Diabetes Care 2009;32 Suppl 1:S62-7.

5. Eaton SB, Eaton SB. Physical inactivity, obesity, and Type 2 diabetes: An evolutionary perspective. Res Q Exerc Sport 2017;88:1-8.

6. World Health Organization 10 Facts about Diabetes. April, 2016. Available from: http:/www.who.int/features/factfiles/diabetes/en/ index.html. [Last cited on 2017 Oct 12].

7. American Diabetes Association. Diagnosis and classification of diabetes mellitus. Diabetes Care 2014;37 Suppl 1:S62-9.

8. Fauci AS, Braunwald E, Kasper DL, Hauser SL, Longo DL, Jameson JL, et al. Harrison's Principles of Internal Medicine. $17^{\text {th }}$ ed. New York: Mc Graw-Hill Publisher; 2008. p. 2275.

9. Zargar AH, Sheikh MI, Bashir M, Masoodi SR, Laway BA, Wani AI, et al. Prevalence of GDM in Kashmiri women in Indian subcontinent. Diabetes Res Clin Pract 2004;66:139-45.

10. National Health and Medical Research Council. Guidelines for the Management of Type 2 Diabetes Mellitus. 2005. Available from: www. https://nhmrc.gov.au/guidelines-publications/di7-di8-di9-di10-di11di12-di13. [Last cited on 2017 Sep 06].

11. Klein R, Klein BE, Moss SE, Davis MD, De Mets DL. The Wisconsin epidemiologic study of diabetic retinopathy. III. Prevalence and risk of diabetic retinopathy when age at diagnosis is 30 or more years. Arch Ophthalmol 1984;102:527-32.

12. Klein R, Klein BE, Moss SE, Davis MD, DeMets DL. The Wisconsin epidemiologic study of diabetic retinopathy. II. Prevalence and risk of diabetic retinopathy when age at diagnosis is less than 30 years. Arch Ophthalmol 1984;102:520-6.

13. Klein R, Klein BE, Moss SE, Davis MD, DeMets DL. The Wisconsin epidemiologic study of diabetic retinopathy. IV. Diabetic macular edema. Ophthalmology 1984;91:1464-74.

14. Wareham NJ, O'Rahilly S. The changing classification and diagnosis of diabetes. New classification is based on pathogenesis, not insulin dependence. BMJ 1998;317:359-60.

15. Tight Blood Pressure Control and Risk of Macrovascular and Microvascular Complications in Type 2 Diabetes: UKPDS 38. UK prospective diabetes study group. BMJ 1998;317:703-13.

16. Haslbeck M, Luft D, Neundörfer B, Stracke H, Ziegler D. Diagnosis, Treatment and Follow-up of Diabetic Neuropathy, Diagnosis, Therapy and Follow-up of Sensorimotor Diabetic Neuropathy. $1^{\text {st }}$ ed. German: German Diabetes;

17. Dyck PJ, Sinnreich M. Diabetic neuropathies. Continuum 2003; Dyck PJ, Sinnreich M. Diabetic neuropathies. Continuum 2003; 9:19-34. 919-34.

18. Edwards JL, Vincent AM, Cheng HT, Feldman EL. Diabetic neuropathy: 
Mechanisms to management. Pharmacol Ther 2008;120:1-34

19. Boulton AJ, Vinik AI, Arezzo JC, Bril V, Feldman EL, Freeman R, et al. American diabetes association diabetic neuropathies: A statement by the American diabetes association. Diabetes Care 2005;28:956-62.

20. Watkins PJ. Pain and diabetic neuropathy. Br Med J 1984;288:168, 169.

21. Tesfaye S, Price D. In: Boulton AJ, editor. Therapeutic Approaches in Diabetic Neuropathy and Neuropathic Pain, in Diabetic Neuropathy. Carnforth, Lancashire, UK: Marius Press; 1997, pp. 159-81.

22. Llewelyn JG. The diabetic neuropathies: Types, diagnosis and management. J Neurol Neurosurg Psychiatry 2003;74 Suppl II:ii15-9.

23. Gorson KC, Schott C, Herman R, Ropper AH, Rand WM. Gabapentin in the treatment of painful diabetic neuropathy: A placebo controlled, double blind, crossover trial. J Neurol Neurosurg Psychiatry 1999;66:251-2.

24. Bansal V, Kalita J, Mishra UK. Diabetic neuropathy. Postgrad Med J 2006;82:95-100

25. Diabetic Neuropathies: The Nerve Damage of Diabetes. National Institutes of Health, U.S. Department of Health and Human Services, February 2009. Available from: https://www.niddk.nih.gov/healthinformation/diabetes/overview/preventing-problems/nerve-damagediabetic-neuropathies. [Last cited on 2017 Nov 18].

26. Dyck PJ, Norell JE, Tristler H. Challenges in design of multicenter trials, end point assessed longitudinally for change and monotonicity. Diabetes Care 2007;30:2619-25

27. Hébert HL, Veluchamy A, Torrance N, Smith BH. Risk factors for neuropathic pain in diabetes mellitus. Pain 2017;158;560-8.

28. Boulton AJ, Vinik AI, Arezzo JC, Bril V, Feldman EL, Freeman R, et al. Diabetic neuropathies, a statement by the American diabetes association. Diabetes Care 2005;28:956-62.

29. Abbott CA, Carrington AL, Ashe H, Bath S, Every LC, Griffiths J, et al. The north-west diabetes foot care study: Incidence of, and risk factors for, new diabetic foot ulceration in a community-based patient cohort. Diabet Med 2002;19:377-84.

30. Diabetes Control of Complications Trial Research Group: The Effect of Intensive Diabetes Therapy on the Development and Progression of Neuropathy. The diabetes control and complications trial research group. Ann Intern Med 1995;122:561-8.

31. Wwlyn JG, Tomlinson DR, Thomas PK, Dyck PJ, Thomas PK. Diabetic Neuropathies in Peripheral Neuropathy. Philadelphia, PA: Elsevier Saunders; 2005. p. 1951-91.

32. Schumer MP, Joyne SA, Pleiffer MA. Cardiovascular autonomic neuropathy testing in patients with diabetes. Diabetes Spectrum 1998; 11:227-31.

33. Yagihashi S, Yamagishi S, Wada R. Pathology and pathogenetic mechanisms of diabetic neuropathy: Correlation with clinical signs and symptoms. Diabetes Res Clin Pract 2007;77 Suppl 1:S184-9.

34. Kawanami D, Matoba K, Utsunomiya K. Signaling pathways in diabetic nephropathy. Histol Histopathol 2016;31:1059-67.

35. Oates PJ. Aldose reductase still a compelling target for diabetic neuropathy. Curr Drug Targets 2008;9:14-36.

36. Cameron NE, Cotter MA. Potential therapeutic approaches to the treatment or prevention of diabetic neuropathy: Evidence from experimental studies. Diabet Med 1993;10:593-605.

37. Du XL, Edelstein D, Rossetti L, Fantus IG, Goldberg H, Ziyadeh F, et al. Hyperglycemia-induced mitochondrial superoxide overproduction activates the hexosamine pathway and induces plasminogen activator inhibitor-1 expression by increasing sp1 glycosylation. Proc Natl Acad Sci U S A 2000;97:12222-6.

38. Lukic IK, Humpert PM, Nawroth PP, Beirhaus A. The RAGE pathway; Activation and perpetuation in the pathogenesis of neuropathy. Ann N Y Acad Sci 2008;1126:76-80.

39. Misur I, Zarković K, Barada A, Batelja L, Milicević Z. Turk advanced glycation of end products in peripheral nerve in Type 2 diabetes with neuropathy. Acta Diabetol 2004;41:158-66.

40. Feighner JP. Mechanism of action of antidepressant medications. J Clin Psychiatry 1999;60 Suppl 4:4-11.

41. Dworkin RH, Backonja M, Rowbotham MC, Allen RR, Argoff CR, Bennett GJ, et al. Advances in neuropathic pain: Diagnosis, mechanisms, and treatment recommendations. Arch Neurol 2003;60:1524-34.

42. Saarto T, Wiffen PJ. Antidepressants for neuropathic pain: A Cochrane review. J Neurol Neurosurg Psychiatry 2010;81:1372-3.

43. Haanpää ML, Gourlay GK, Kent JL, Miaskowski C, Raja SN, Schmader $\mathrm{KE}$, et al. Treatment considerations for patients with neuropathic pain and other medical comorbidities. Mayo Clin Proc 2010;85:S15-25.

44. Trindade E, Menon D, Topfer LA, Coloma C. Adverse effects associated with selective serotonin reuptake inhibitors and tricyclic antidepressants: A meta-analysis. CMAJ 1998;159:1245-52.
45. Roose SP, Laghrissi-Thode F, Kennedy JS, Nelson JC, Bigger JT Jr., Pollock BG, et al. Comparison of paroxetine and nortriptyline in depressed patients with ischemic heart disease. JAMA 1998;279:287-91.

46. Lunn MP, Hughes RA, Wiffen PJ. Duloxetine for treating painful neuropathy or chronic pain. Cochrane Database Syst Rev 2009; 4:CD007115

47. Saarto T, Wiffen PJ. Antidepressants for neuropathic pain. Cochrane Database Syst Rev 2007;3:CD005454.

48. Max MB, Lynch SA, Muir J, Shoaf SE, Smoller B, Dubner R, et al. Effects of desipramine, amitriptyline, and fluoxetine on pain in diabetic neuropathy. N Engl J Med 1992;326:1250-6.

49. Sindrup SH, Gram LF, Brøsen K, Eshøj O, Mogensen EF. The selective serotonin reuptake inhibitor paroxetine is effective in the treatment of diabetic neuropathy symptoms. Pain 1990;42:135-44.

50. Sindrup SH, Bjerre U, Dejgaard A, Brøsen K, Aaes-Jørgensen T, Gram LF, et al. The selective serotonin reuptake inhibitor citalopram relieves the symptoms of diabetic neuropathy. Clin Pharmacol Ther 1992;52:547-52

51. Raja RK. Painful diabetic neuropathy, continuing education in anaesthesia. Critical Care Pain 2014;14:197-201.

52. Vinik A. Clinical review: Use of antiepileptic drugs in the treatment of chronic painful diabetic neuropathy. J Clin Endocrinol Metab 2005;90:4936-45.

53. LaRoche SM, Helmers SL. The new antiepileptic drugs: Scientific review. JAMA 2004;291:605-14

54. Harati Y, Gooch C, Swenson M, Edelman SV, Greene D, Raskin P, et al. Maintenance of the long-term effectiveness of tramadol in treatment of the pain of diabetic neuropathy. J Diabetes Complications 2000;14:65-70.

55. Martini C, Yassen A, Olofsen E, Passier P, Stoker M, Dahan A. Pharmacodynamic analysis of the analgesic effect of capsaicin $8 \%$ patch (QutenzaTM) in diabetic neuropathic pain patients: Detection of distinct response groups. J Pain Res 2012;5:51-9.

56. Quilici S, Chancellor J, Löthgren M, Simon D, Said G, Le TK, et al. Metaanalysis of duloxetine vs. pregabalin and gabapentin in the treatment of diabetic peripheral neuropathic pain. BMC Neurol 2009;9:6.

57. Gilron I, Bailey JM, Tu D, Holden RR, Jackson AC, Houlden RL. Nortriptyline and gabapentin, alone and in combination for neuropathic pain: A double-blind, randomised controlled cross over trial. Lancet 2009;374:1252-61.

58. Kochar DK, Jain N, Agarwal RP, Srivastava T, Agarwal P, Gupta S. Sodium valproate in the management of painful neuropathy in Type 2 diabetes-a randomized placebo controlled study. Acta Neurol Scand 2002;106:248-52.

59. Beydoun A, Shaibani A, Hopwood M, Wan Y. Oxcarbazepine in painful diabetic neuropathy: Results of a dose-ranging study. Acta Neurol Scand 2006;113:395-404.

60. Dogra S, Beydoun S, Mazzola J. Oxcarbazepine in painful diabetic neuropathy: A randomized, placebo-controlled study. Eur J Pain 2005;9:543-54.

61. Eisenberg E, Lurie Y, Braker C, Daoud D. Lamotrigine reduces painful diabetic neuropathy: A randomized, controlled study. Neurology 2001;57:505-9.

62. Raskin J, Pritchett YL, Wang F, D'Souza DN, Waninger AL, Iyengar S, et al. A double-blind, randomized multicenter trial comparing duloxetine with placebo in the management of diabetic peripheral neuropathic pain. Pain Med 2005;6:346-56.

63. Wright JM, Oki JC, Graves L. Mexiletine in the symptomatic treatment of diabetic peripheral neuropathy. Ann Pharmacother 1997:31:29-34.

64. Watson CP, Moulin D, Watt-Watson J, Gordon A, Eisenhoffer J. Controlled-release oxycodone relieves neuropathic pain: A randomized controlled trial in painful diabetic neuropathy. Pain 2003;105:71-8.

65. Goldstein DJ, Lu Y, Detke MJ, Lee TC, Iyengar S. Duloxetine vs. placebo in patients with painful diabetic neuropathy. Pain 2005;116: 109-18.

66. Lton AJ, Grics FA, Tevel JA. Guidelines for the diagnosis and outpatient management of diabetic peripheral neuropathy. Diab Med 1998;15:508-14.

67. Lton AJM, Malik RA, Arezzo JC. Diabetic somatic neuropathy, technical review. Diabetes Care 2004;27:1458-87.

68. Coppey LJ, Davidson EP, Dunlap JA, Lund DD, Yorek MA. Slowing of motor nerve conduction velocity in streptozotocin-induced diabetic rats is preceded by impaired vasodilation in arterioles that overlie the sciatic nerve. Int J Exp Diabetes Res 2000;1:131-43.

69. Erbas O, Oltulu F, Yılmaz M, Yavaşo A, Taşkıran D. Neuroprotective effects of chronic administration of levetiracetam in a rat model of diabetic neuropathy. Diabetes Res Clin Pract 2016;114:106-16.

70. Malaisse WJ, Malaisse-Lagae F, Sener A, Pipeleers DG. Determinants 
of the selective toxicity of alloxan to the pancreatic B cell. Proc Natl Acad Sci U S A 1982;79:927-30.

71. Mathews CE, Leiter EH. Constitutive differences in antioxidant defense status distinguish alloxan-resistant and alloxan-susceptible mice. Free Radic Biol Med 1999;27:449-55

72. Walde SS, Dohle C, Schott-Ohly P, Gleichmann H. Gleichmann H. Molecular target structures in alloxan-induced diabetes in mice. Life Sci 2002;71:1681-94.

73. Kim HR, Rho HW, Park BH, Park JW, Kim JS, Kim UH, et al. Role of ca2 + in alloxan-induced pancreatic beta-cell damage. Biochim Biophys Acta 1994;1227:87-91

74. Szkudelski T. The mechanism of alloxan and streptozotocin action in B cells of the rat pancreas. Physiol Res 2001;50:537-46.

75. Wang J, Wan R, Mo Y, Zhang Q, Sherwood LC, Chien S, et al. Creating a long-term diabetic rabbit model. Exp Diabetes Res 2010;2010:289614.

76. Andayani TN, Ibrahim MIM, Asdie AH. The association of diabetes related factor and quality of life in Type 2 diabetes mellitus. Int J Pharm Pharm Sci 2010;2:72-5.

77. Apfel SC. Neurotrophic factors in the therapy of diabetic neuropathy. Am J Med 1999;107 Suppl:34S-42.

78. Bhadada SK, Sahay RK, Jyotsna VP, Agrawal JK. Diabetic neuropathy: Current concepts. J Indian Acad Clin Med 2001;2:305-16.

79. Bordoloi R, Dutta KN. A review on herbs used in the treatment of diabetes mellitus. J Pharm Chem Biol Sci 2014;2:86-92

80. Rupeshkumar M, Kavith K, Haldar PK. Role of herbal plants in the diabetes mellitus therapy: An overview. Int J Appl Pharm 2014;6:1-3.

81. Ibrahim R. Diabetes mellitus Type II: Review of oral treatment options. Int J Pharm Pharm Sci 2010;2:36-41. 